\title{
Molecular changes in the phosphatidylinositide 3-kinase (PI3K) pathway are common in gastric cancer
}

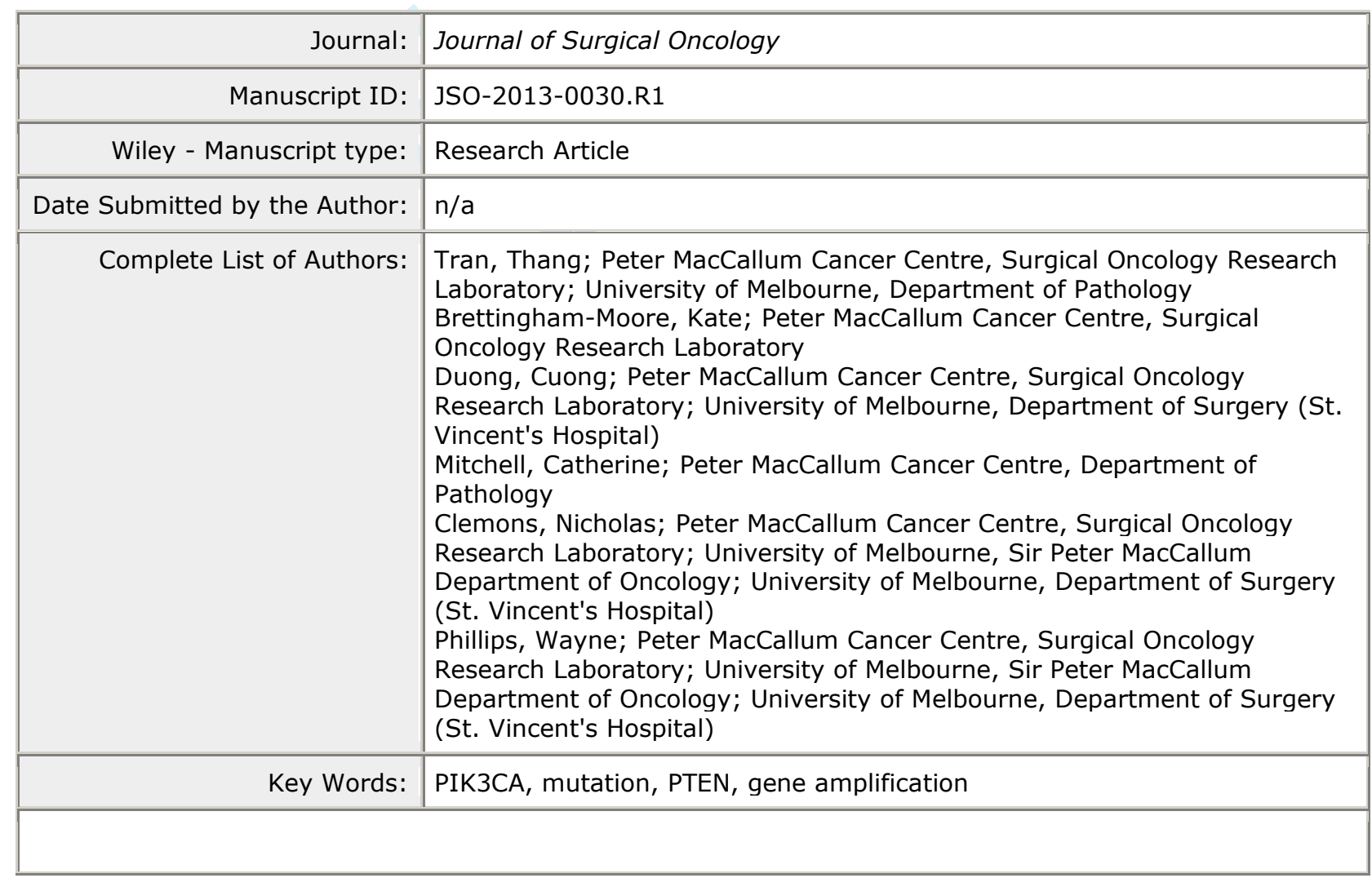




\section{Molecular changes in the phosphatidylinositide 3-kinase (PI3K) pathway are common} in gastric cancer

Thang Nam Tran MD MPhil ${ }^{1,5}$, Kate Brettingham-Moore $\mathrm{PhD}^{1}$, Cuong Phu Duong MB BS $\mathrm{PhD}^{1,4}$, Catherine Mitchell MB BS${ }^{2}$, Nicholas J. Clemons $\mathrm{PhD}^{1,3,4}$, and Wayne A. Phillips $\operatorname{PhD}{ }^{1,3,4 *}$

${ }^{1}$ Surgical Oncology Research Laboratory and ${ }^{2}$ Department of Pathology, Peter MacCallum Cancer Centre, Melbourne, Victoria, Australia; ${ }^{3}$ Sir Peter MacCallum Department of Oncology, and Departments of ${ }^{4}$ Surgery (St. Vincent Hospital) and ${ }^{5}$ Pathology, University of Melbourne, Parkville, Victoria, Australia.

*Address correspondence:

Wayne A. Phillips PhD, Surgical Oncology Research Laboratory, Peter MacCallum Cancer Centre, Locked bag 1 A'Beckett Street, Melbourne, Victoria 8006, AUSTRALIA'

Phone: +61 39656 1842; Fax: +61 39656 1400; E-mail: wayne.phillips@ petermac.org

Running head: PI3K pathway alterations in gastric cancer

Synopsis: Human gastric tumours were found to harbour a high frequency of molecular changes in the PI3K pathway including PIK3CA mutation (5\%), PIK3CA copy number gain (13\%) and PTEN loss (39\%). These results are consistent with an important role for the PI3K pathway in gastric tumourigenesis and identify the PI3K pathway as a potential therapeutic target in gastric cancer. 


\begin{abstract}
Background and Objectives. The phosphatidylinositide 3-kinase (PI3K) pathway is an important signaling pathway that is frequently activated in cancer cells. This has led to the emergence of PI3K inhibitors as potential new treatment modalities for many cancers. We have investigated the frequency of molecular changes in the PI3K pathway in gastric cancer.

Methods. A series of sixty one human gastric cancer specimens and nine human gastric cancer cell lines were screened for PIK3CA mutations and copy number gain by direct sequencing and multiplex ligation-dependent probe amplification (MLPA), respectively. PTEN protein levels were assessed by immunohistochemistry.

Results. Alterations in the PI3K pathway were found in 33 of 61 (54\%) gastric tumours. PIK3CA mutation and copy number gain were detected in $3(4.9 \%)$ and $8(13.1 \%)$, respectively, of 61 gastric cancer samples while PTEN loss was detected in 24 (39\%) of the tumours. Two tumours had both PTEN loss and PIK3CA copy number gain. There were no significant associations between these PI3K pathway changes and the clinical features of the tumours.
\end{abstract}

Conclusions. Alterations in the PI3K pathway are frequent in gastric tumours implicating this pathway as a legitimate therapeutic target in gastric cancer.

Key words: $P I K 3 C A$, mutation, gene amplification, PTEN, tissue microarray 


\section{BACKGROUND}

Gastric cancer is of major importance worldwide, being the second most common cause of cancer-related death in the world [1]. Despite its decreasing incidence, gastric cancer is still a challenging disease. Apart from countries with established national screening programs like Japan and Korea, gastric cancer patients are often diagnosed with advanced tumours and their prognoses remain poor. Conventional systemic chemotherapy when combined with surgical tumour resection yields only modest improvement in survival for patients with resectable gastric cancer [2]. The knowledge of molecular pathways implicated in gastric cancer pathogenesis is still in its infancy and the contribution of molecular biology to the development of new-targeted therapies in gastric cancer is far behind other more common cancers such as breast, colon or lung [3].

The phosphatidylinositide 3-kinase (PI3K) pathway is an important intracellular pathway that is frequently activated in cancer cells [4,5]. Increased levels of phosphorylated AKT (pAKT), downstream of PI3K signaling, and low expression or mutation of PTEN, a negative regulator of PI3K signaling, have been shown to be involved in breast, ovarian and colon cancers [5-7]. This has led to the emergence of PI3K inhibitors as potential new treatment modalities [8].

Alterations in the PI3K pathway have been documented in several gastric cancer studies [913], although, these are limited in their sample size or vary significantly in the prevalence of PIK3CA mutations. Furthermore, little additional work has been performed on clinicopathologic correlates of PIK3CA in this tumour type. Similarly, reports on PIK3CA amplification and $A K T$ mutation are limited with only a few reports published to date $[9,10]$. It is also not well understood how PIK3CA amplification qualitatively or quantitatively 
affects PI3K signaling and whether it obviates the usual mechanisms for activating PI3K pathway.

Overall, the evidence for a role of PI3K in cancer progression and the lack of a comprehensive study of PI3K pathway alterations in a simultaneous series of gastric cancer samples, demonstrate the need for further investigations in this area. Investigating the significance of PI3K/AKT/PTEN pathway alterations in gastric cancer and potential associations with clinicopathologic features may help determine prognosis and identify a subset of patients who might be candidates for new molecular therapies targeting the PI3K pathway. We therefore undertook a retrospective study to investigate the frequency of molecular changes in the PI3K pathway in gastric cancer.

\section{MATERIALS AND METHODS}

\section{Materials}

Tissue samples. Sixty one fresh primary gastric tumour specimens and corresponding nonmalignant adjacent gastric tissues were collected from consecutive patients undergoing surgery at Western Hospital, Footscray, Victoria, Australia, between 1993 and 1999. Most patients (55/61) had curative surgery with clear surgical margins, in the form of either partial $(67.2 \%)$ or total $(23 \%)$ gastrectomies. The majority had D1 lymphadenectomy and the mean number of lymph nodes resected was $14 \pm 7$ (mean \pm SEM; range $=2$ - 34). Six cases were unresectable and the samples collected by biopsy. Of these, 1 case was unresectable due to invasion into both the lower oesophagus and the pancreas, 1 because of invasion into the posterior abdominal wall, and 4 as a result of peritoneal metastases. Thirteen (21\%) of the tumours were located in the cardia (defined as the upper third of the stomach) including 3 
that had total gastric involvement. The remaining 48 (79\%) were restricted to the lower two thirds of the stomach.

The samples were cut into small pieces $\left(\sim 3 \mathrm{~mm}^{3}\right)$, snap frozen in liquid nitrogen (and/or embedded in OCT), and stored at $-80^{\circ} \mathrm{C}$. The original collection of tissue and patient data was approved by the Research and Ethics Committee of Western Hospital and the use of the samples in the current study was approved by the Human Ethics Committee of the Peter MacCallum Cancer Centre.

Cell lines. Gastric cancer cell lines AGS, KATO-III, SNU1, SNU5, SNU16, N87, and Hs746T were obtained from ATCC (American Type Culture Collection). Two other gastric cancer cell lines (GTL-16, and MKN28) were a gift from Rita Busuttil, Peter MacCallum Cancer Centre. Cell lines were maintained at $37^{\circ} \mathrm{C}$ and $5 \% \mathrm{CO}_{2}$ in RPMI-1640 growth medium supplemented with $10 \%$ fetal bovine serum (FBS).

\section{Methods}

\section{DNA assays}

DNA extraction. DNA was extracted from biopsies and cell lines using the QIAamp DNeasy Blood and Tissue Kit (Qiagen, Chadstone, Victoria, Australia) according to the manufacturer's instructions.

PIK3CA sequencing. Exons 7, 9 and 20 of PIK3CA were amplified from genomic DNA with primers complementary to the surrounding intronic sequences using the HotStarTaq DNA Polymerase (Qiagen). The PCR products were then directly sequenced using capillary sequencer ABI PRISM 3130 (Applied Biosystems, Mulgrave, Victoria, Australia). The sequencing data was analysed using AlignX program of Vector NTI 11.0 software. The chromograms were also checked with Chromas LITE version 2.01 software. Mutations were read out using mutation nomenclature of the Human Genome Variation Society [14]. 
Multiplex ligation-dependent probe amplification (MLPA). MLPA was performed with the SALSA MLPA P173 Gain kit (MRC-Holland, Amsterdam, the Netherlands) according to the manufacturer's instructions. The thresholds of MLPA ratio for result interpretation were < 0.7 (copy number loss); 0.7-1.3 (normal); 1.3-3 (copy number gain); > 3 (amplification). The P173 probemix contains 3 different probes for PIK3CA gene and copy number gain/amplification was defined by 2 or more of the probes having ratios of $>1.3 />3$, respectively.

Mutation detection by high-resolution DNA melting (HRM). The AKT1 E17K mutation in Exon 4 was screened using HRM analysis. Exon 4 of $A K T 1$ was amplified from genomic DNA with primers complementary to surrounding intronic sequences. PCR cycling and HRM analysis was performed on the Light Cycler® 480 (Roche, Hawthorn, Victoria, Australia). LightCycler® 480 Software (v1.3.0.0705) was used to analyse data. Samples showing deviations in melting curve were treated with ExoSapIT® (Affymetrix, Cleveland, OH, USA) according to the manufacturer's instructions and sequenced directly with the BigDye ${ }^{\circledR}$ terminator method (Applied Biosystems) on a capillary sequencer ABI PRISM® 3130 (Applied Biosystems).

Tissue microarray (TMA) construction. Fresh frozen or OCT-embedded tissue samples from all 61 tumours used for the genetic studies were formalin fixed and embedded in paraffin. A haematoxylin and eosin $(\mathrm{H} \& \mathrm{E})$ stained section was obtained from each tissue for the reevaluation of tissue preservation and diagnosis as well as marking up tumour or normal mucosal areas by an anatomical pathologist. A tissue microarray (TMA) was constructed using a manual tissue arrayer (Advanced Tissue Arrayer - ATA100, Chemicon Australia, Boronia, Victoria, Australia). One or two representative $1 \mathrm{~mm}$ cores from each case were taken for the array. An additional 24 cores of cancer cell blocks (human gastric and prostate cancer cell lines, prepared as below) and 3 human liver cores were also arrayed. The prostate 
cancer cell block and liver cores were used as control material and orientation markers, respectively.

Cell block preparation. Cell blocks were prepared as described previously [15]. Briefly, cells were cultured in a T75 flask until 70-90\% of confluence. After washing with PBS, trypsinising and spinning down the cells, the cell pellet was fixed with $1 \mathrm{ml}$ of $10 \%$ neutral buffered formalin for $10 \mathrm{~min}$, resuspended in $50 \mu \mathrm{l}$ of pre-warmed $4 \%$ nutrient agar, and placed at $4^{\circ} \mathrm{C}$ to form a suspended cell block. Finally, the cell block was transferred to a tissue cassette and embedded in paraffin.

Immunohistochemistry. The TMA slides were de-waxed and hydrated through graded alcohol and distilled water using an autostainer. Antigen retrieval was done using EnVision ${ }^{\mathrm{TM}}$ Target Retrieval Solution (Dako Australia, Campbellfield, Victoria, Australia), at high pH in a pressure cooker. Immunohistochemical staining was performed using primary antibodies and EnVision ${ }^{\mathrm{TM}}$ FLEX DAB + Chromogen (Dako). All antibodies used were from Cell Signaling Technology® (Danvers, MA, USA) and were diluted in 5\% bovine serum albumin in TrisBuffered Saline (TBS; $50 \mathrm{mM}$ Tris, $150 \mathrm{mM} \mathrm{NaCl}$, pH 7.6) as follows: PTEN rabbit monoclonal antibody (138G6, cat\#9559), 1:100; pAKT (Ser473) rabbit monoclonal antibody (736E11, cat\#3787), 1:50; PI3K p110 $\alpha$ rabbit monoclonal antibody (C73F8, cat\#4249), 1:200. A section was also stained with H\&E stain to confirm diagnosis and enable correlation of immunohistochemical staining with histology.

Immunohistochemical scoring. All slides were assessed blinded to clinical data. PTEN and p-AKT staining were scored using an intensity scale ranging from 0 to 3: 0 , no appreciable staining in tumour cells; 1 , barely detectable staining in tumour cells; 2 , readily appreciable staining in tumour cells; 3, intense staining in tumour cells. For purposes of analysis, all cases staining at level 0 or 1 were grouped as pAKT low and all cases staining at level 2 and level 3 were grouped as pAKT high. For PTEN scoring cases staining at level 2 or 3 were 
considered as normal expression and cases staining at level 0 or 1 were considered to have PTEN loss. For PIK3CA protein (p110 $\alpha$ staining), each TMA spot was assigned an intensity score from 0-3 as above $\left(\mathrm{I}_{0}, \mathrm{I}_{1-3}\right)$, and the proportion of the tumour staining for that intensity was recorded as $5 \%$ increments from a range of 0-100 $\left(\mathrm{P}_{0}, \mathrm{P}_{1-3}\right)$. A final 'H score' (range 0300) was obtained by adding the sum of scores obtained for each intensity and proportion of area stained $\left(\mathrm{H}\right.$ score $\left.=\mathrm{I}_{1} \times \mathrm{P}_{1}+\mathrm{I}_{2} \mathrm{XP}_{2}+\mathrm{I}_{3} \times \mathrm{P}_{3}\right) \cdot \mathrm{p} 110 \alpha$ expression was grouped as low $\mathrm{p} 110 \alpha$ expression $(H \leq 200)$ and high $\mathrm{p} 110 \alpha$ expression $(\mathrm{H}$ score $\geq 200)$.

\section{Drug assays}

Drugs and reagents. LY294002 (Calbiochem - EMD Millipore, Billerica, MA, USA), 5Fluorouracil (5-FU) (Sigma-Aldrich, Sydney, NSW, Australia) and oxaliplatin (Eloxatin ${ }^{\circledR}$, Sanofi, Macquarie Park, NSW, Australia) were diluted in dimethyl sulfoxide (DMSO) to create a stock that was stored according to the manufacturer's instructions. Alarmar Blue was purchased from Invitrogen $^{\mathrm{TM}}$ (Life Technologies ${ }^{\mathrm{TM}}$, Mulgrave, VIC, Australia).

Cytotoxic assay. The cytotoxicity of chemotherapeutic agents (5-FU and oxaliplatin) or PI3K inhibitor (LY294002) was tested using nine gastric cancer cell lines. Serial drug concentrations were used to determine the $\mathrm{IC}_{50}$ of each cell line for 5-FU, oxaliplatin and LY294002. The gastric cancer cells were seeded at the optimal density and incubated at $37^{\circ} \mathrm{C}, 5 \% \mathrm{CO}_{2}$ overnight to allow for cell attachment. The cells were then treated with drugs in serial diluted concentrations, or DMSO as control, and incubated for 72 hours before adding $10 \%$ volume of Alamar Blue ${ }^{\circledR}$ and incubated for a further 6 hours. Finally, the fluorescent intensity of cells was measured in an OPTIMA micro-plate reader using a fluorescent excitation wavelength of 540-570 $\mathrm{nm}$. The $\mathrm{IC}_{50}$ of each drug for each cancer cell line was calculated based on the proportion of fluorescent intensity of treated cells and control cells. Finally, drug combinations were tested at constant ratios based on the estimated 
$\mathrm{IC}_{50}$ of each drug for each cancer cell line. All experiments were carried out in triplicate and replicated at least twice.

Data analysis. The calculations of $\mathrm{IC}_{50}$ and combination index were based on Chou and Talalay theory and CalcuSyn software version 2.1 [16]. Doses were calculated by the formula: $\mathrm{D}=\mathrm{Dm}[\mathrm{Fa} /(1-\mathrm{Fa})] / \mathrm{m}$; where $\mathrm{Dm}$ is $\mathrm{IC}_{50}$, the dose required for $50 \%$ growth inhibition, $\mathrm{Fa}$ is the fraction affected and $\mathrm{m}$ is the slope. The combination index (CI) was calculated using the following formula:

$$
\mathrm{CI}=[(\mathrm{D}) 1 /(\mathrm{Dx}) 1]+[(\mathrm{D}) 2 /(\mathrm{Dx}) 2]+[\mathrm{a}(\mathrm{D}) 1(\mathrm{D}) 2 /(\mathrm{Dx}) 1(\mathrm{Dx}) 2] \text {; }
$$

Where a=1 for mutually non-exclusive drugs, (D) 1 and (D) 2 are the doses of the separate drugs and the combination, and (Dx)1 and (Dx)2 are the doses resulting in a growth inhibition of $\mathrm{x} \%$. A CI of $<0.9,0.9-1.1$, or $>1.1$ indicates synergism, additivity, or antagonism respectively.

\section{RESULTS}

\section{$\underline{\text { PI3K alterations in gastric cancer tissues }}$}

A total of 61 human gastric cancer samples were analysed for alterations in various components of the PI3K pathway (Table I).

DNA extracted from the samples was screened for somatic mutations in exons 9 and 20 of PIK3CA and exon 4 of $A K T 1$, and for PIK3CA copy number. Three missense PIK3CA mutations were identified (4.9\% of tumours); one of the mutations was identified in exon 9 (c.1615C>T; p.P539S) and two were found in exon 20 (c.3140A>G: p.H1047R) (Table 1). No mutations were detected in corresponding adjacent non-malignant mucosa indicating that the mutations are somatic. Two tumours were found to harbour silent somatic changes in exon 20 (c.3075C>T; p.T1025T) but as this sequence change does not alter the protein 
sequence these were considered likely to be non-pathogenic passenger polymorphisms and not considered further. No mutations were detected in $A K T 1$.

PIK3CA copy number gains were detected in 8 of $61(13.1 \%)$ gastric tumour samples (Table 1). Seven of the 8 samples with copy number gain also had high (above average) p110 $\alpha$ protein expression. None of the tumours with a $P I K 3 C A$ copy number gain harboured a PIK3CA mutation.

Immunohistochemistry was used to assess the level of PTEN protein expression in 61 gastric tumours and identified 24 (39\%) with loss of PTEN protein (Figure 1). Interestingly, two of these tumours also had PIK3CA copy number gain but none harboured a PIK3CA mutation (Table 1).

pAKT levels were examined as a surrogate marker for PI3K pathway activity. Twenty eight tumours $(46 \%)$ were classed as having high pAKT levels (Figure 1). These included 6 of the 8 tumours with PIK3CA gain and 2 of the 3 with PIK3CA mutation. Interestingly, loss of PTEN was significantly associated with low pAKT (Table II).

The changes in PI3K pathway were compared to clinical features of the tumours (Table III). Interestingly, there was an association with tumour location with tumours in the cardia having significantly less alterations in the PI3K pathway than non-cardia tumours $(\mathrm{p}=0.03)$. No other significant clinical associations were found but this may be a reflection of the relatively small numbers of PI3K alterations in some groups resulting in limited statistical power to detect differences (type II error).

\section{$\underline{\text { PI3K alterations in gastric cancer cell lines }}$}

The genetic alterations related to PI3K pathway were also examined in nine human gastric cancer cell lines. The AGS cell line was found to harbour the PIK3CA mutation c.1357G >A 
(p.E453K). (We also detected a c.1634A $>\mathrm{C}$ base change in PIK3CA in this cell line, however, the significance of this change is unclear as this has been suggested to be due to the presence of a pseudogene on chromosome 22 [17,18].) PIK3CA copy number gains were identified in KATO-III, GTL-16 and Hs746T (Table IV). All three of the cell lines with PIK3CA gain had above average expression of p110 $\alpha$ protein as assessed by immunohistochemistry (data not shown).

The levels of pAKT and PTEN protein were also assessed by immunohistochemistry (Figure 2). PTEN was found to be lost in 2 cell lines (SNU-16) and MKN-28). pAKT levels were found to be high in 6 of the 9 cell lines including all those with PIK3CA mutation or gain and one of the two with PTEN loss (Table IV).

Sensitivity of gastric cancer cell lines to the PI3K inhibitor LY294002.

LY294002 significantly inhibited the proliferation of AGS, SNU-1, MKN-28, N87, GTL-16, and Hs746T with $\mathrm{IC}_{50}$ values of less than $30 \mu \mathrm{M}$. Much higher doses of LY294002 (>500 $\left.\mu \mathrm{M}\right)$ were required to inhibit the proliferation of the KATO-III, SNU-5, and SNU-16 cell lines (Figure 3, Table V).

Synergistic effects of PI3K inhibition with chemotherapeutic agents.

The combination of LY294002 with oxaliplatin and 5-FU were tested (using constant ratios between LY294002 and 5-FU or oxaliplatin) in cell lines with a computable $\mathrm{IC}_{50}$ value. A synergistic effect was found in AGS and SNU-1 cell lines when 5-FU was combined with LY294002 (combination index $<0.9$ at effect dose of $75 \%$ and $90 \%$ growth inhibition). Synergism was also detected between LY294002 and oxaliplatin in the Hs746T cell line (Figure 4, Table V). 


\section{DISCUSSION}

After more than half a decade since first reports of PIK3CA mutations in human cancers, genetic alterations in PIK3CA have been investigated in large-scale studies in a variety of human cancers as well as in sub-types of individual cancers and in different ethnic groups [57,19-22]. COSMIC (Catalogue of Somatic Mutation in Cancer) (http://www.sanger.ac.uk/genetics/CGP/cosmic/), the largest public resource for information on somatically acquired mutations in human cancer, currently lists the frequency of $P I K 3 C A$ mutations in stomach cancers as $12 \%(96 / 823)$ while Barbi et al. have reported an incidence of $16 \%(42 / 262)$ [23]. The incidence of PIK3CA mutation found in gastric cancer in our study (4.9\%) is lower than these but is consistent with previous reports by Li et al. [12] (4.3\%) and Lee et al. (5.1\%) [11]. In addition, in this study PIK3CA copy number gain was found to be more frequent $(13.1 \%)$ than PIK3CA mutations. However, this prevalence was also lower than that previously reported in gastric cancer (36.4\%) [9].

A mutation in the $A K T 1$ gene that results in E17K substitution in the PH domain of $A K T 1$ has been recently reported in a number of human tumours including breast cancer $(5 / 61 ; 8.2 \%)$, colorectal cancer $(3 / 51 ; 5.9 \%)$ and ovarian cancer $(1 / 50 ; 2 \%)[24]$. It was also documented in endometrial cancer $(2.2 \% ; 2 / 89)$ [25]. However, we were unable to detect any E17K mutations in AKT1 in our gastric cancer cohort. This is consistent with the work of Kim et al., who examined a variety of tumour types and detected $A K T 1$ E17K mutations in 4 of 93 breast cancers but none of 180 gastric adenocarcinomas [10]. Similarly, Soung et al. who found no AKT1 mutations (but 1 AKT2 mutation) in 51 gastric cancers [26]. 
PTEN, a well characterised tumour suppressor gene, is a known negative regulator of the PI3K pathway and loss of PTEN has been reported in many tumour types [27]. Consistent with a previous report [9], we detected PTEN loss in 24 of the 61 tumours (39\%).

In general, the abnormalities detected in the PI3K pathway in our study were mutually exclusive. Only 2 tumours contained more than one alteration and both of these had PIK3CA gain and PTEN loss.

The overall activity of the PI3K pathway was assessed using the phosphorylation of AKT as a surrogate marker of PI3K pathway activity. The number of samples with $P I K 3 C A$ mutations was too small to draw any conclusions regarding an association with pAKT levels but the 2 tumours with the common H1047R mutation both exhibited above average pAKT levels. Also, 6 of the 8 tumours with PIK3CA gain had high pAKT, as did the 3 cell lines with PIK3CA gain. Interestingly, the 2 tumours with PIK3CA gain that did not have high pAKT were those that had also lost PTEN (Table I). Indeed, in general, PTEN loss was found to be significantly associated with low pAKT levels ( $\mathrm{p}=0.002$, Table II), a finding that is perhaps surprisingly given PTENs known role as a negative regulator of the PI3K pathway. However, not only is the regulation of the PI3K pathway complex with abundant cross-talk and feed-back loops but Akt is not the only downstream effector of PI3K [28]. It is thus possible that in the absence of PTEN the increased PI3K activity in these tumours is directed through other alternative effector molecules.

Apart from an apparent preponderance of PI3K pathway abnormalities in the non-cardia gastric tumours, compared to tumours in the cardia, there were no significant clinical associations detected. However, it must be acknowledged that we cannot rule out the possibility that our sample numbers may be too small to detect clinically relevant associations (type II errors). We are also unable to comment on any potential association between PI3K changes and survival as we, unfortunately, did not have access to appropriate follow-up data. 


\section{Activation of PI3K pathway in gastric cancer cell lines}

In order to identify a model system in which to test potential therapeutic agents, we investigated the activation of the PI3K pathway in a series of established gastric cancer cell lines. Two thirds (6/9) of the cell lines had increased PI3K pathway activity as evidenced by high pAKT (Table IV). In most cases this was consistent with the presence of a detectable molecular alteration in the PI3K pathway (PIK3CA mutation or copy number gain or PTEN loss). While this correlation was not absolute, it is possible that some of the cell lines may have PI3K pathway alterations that have not been identified in our limited screen. Nevertheless, the overwhelming evidence for a role for the PI3K pathway activation in the initiation and/or progression of tumourigenesis makes the PI3K pathway a logical target for therapeutic intervention. Consistent with this, many of the cell lines tested in this study were found to be sensitive to the PI3K inhibitor LY294002 (Table IV).

It is noteworthy that two of the gastric cancer cell lines (KATO-III and SNU-16) were found to be insensitive to LY294002 even though they have genetic abnormalities in the PI3K pathway and demonstrated upregulation of pAKT protein. This suggests that the presence of genetic abnormalities in the PI3K pathway may not necessarily be the optimal marker for sensitivity to PI3K inhibitors. Interestingly, both of these cell lines have previously been shown to also harbor a p53 mutation [29,30]. Recently, several studies have reported that LY294002 induces apoptosis in a p53-dependent manner [31-33]. Thus, p53 mutation might be a possible reason for the insensitivity to LY294002 in these cell lines.

In addition to its potential as a direct target, previous studies have demonstrated that PI3K activation is associated with resistance to chemotherapy and radiotherapy [34,35]. This raises the possibility that inhibition of PI3K might be effective in combination with conventional 
therapeutic agents. Oxaliplatin and 5-FU are conventional cytotoxic agents that are commonly used to treat gastric cancers. Our results show that 5-FU in combination with LY294002 had a synergistic effect in AGS and SNU-1 cell lines, while oxaliplatin and LY294002 were synergistic in the Hs746T cell line. These observations, although preliminary in nature, support the exploration of combination therapies using PI3K inhibitors together with conventional chemotherapeutic agents.

\section{CONCLUSIONS}

Our results are consistent with an important role of the PI3K pathway in gastric tumourigenesis and identify the PI3K pathway as a legitimate therapeutic target in gastric cancer. Further studies are needed to fully understand the mechanism underlying the action of the PI3K pathway and to identify patients most likely to respond to PI3K-targeted therapies.

\section{ACKNOWLEDGEMENTS}

TNT was the recipient of a University of Melbourne Postgraduate Research Scholarship. WAP and NJC were supported, in part, by project grants from the National Health and Medical Research Council (NHMRC) of Australia.

\section{REFERENCES}

1. Jemal A, Bray F, Center MM, et al.: Global cancer statistics. CA Cancer J Clin 2011;61:69-90.

2. Paoletti X, Oba K, Burzykowski T, et al.: Benefit of adjuvant chemotherapy for resectable gastric cancer: a meta-analysis. JAMA 2010;303:1729-1737.

3. Arkenau HT: Gastric cancer in the era of molecularly targeted agents: current drug development strategies. J Cancer Res Clin Oncol 2009;135:855-866. 
4. Bader AG, Kang S, Zhao L, Vogt PK: Oncogenic PI3K deregulates transcription and translation. Nat Rev Cancer 2005;5:921-929.

5. Samuels Y, Wang Z, Bardelli A, et al.: High frequency of mutations of the PIK3CA gene in human cancers. Science 2004;304:554.

6. Campbell IG, Russell SE, Choong DY, et al.: Mutation of the PIK3CA gene in ovarian and breast cancer. Cancer Res 2004;64:7678-7681.

7. Philp AJ, Campbell IG, Leet C, et al.: The phosphatidylinositol 3'-kinase p85alpha gene is an oncogene in human ovarian and colon tumors. Cancer Res 2001;61:7426-7429.

8. Sheppard K, Kinross KM, Solomon B, et al.: Targeting PI3 kinase/AKT/mTOR signaling in cancer. Crit Rev Oncog 2012;17:69-95.

9. Byun DS, Cho K, Ryu BK, et al.: Frequent monoallelic deletion of PTEN and its reciprocal associatioin with PIK3CA amplification in gastric carcinoma. Int J Cancer 2003;104:318-327.

10. Kim MS, Jeong EG, Yoo NJ, Lee SH: Mutational analysis of oncogenic AKT E17K mutation in common solid cancers and acute leukaemias. Br J Cancer 2008;98:1533-1535.

11. Lee JW, Soung YH, Kim SY, et al.: PIK3CA gene is frequently mutated in breast carcinomas and hepatocellular carcinomas. Oncogene 2005;24:1477-1480.

12. Li VS, Wong CW, Chan TL, et al.: Mutations of PIK3CA in gastric adenocarcinoma. BMC Cancer 2005;5:29.

13. Velho S, Oliveira C, Ferreira A, et al.: The prevalence of PIK3CA mutations in gastric and colon cancer. Eur J Cancer 2005;41:1649-1654.

14. den Dunnen JT, Antonarakis SE: Mutation nomenclature extensions and suggestions to describe complex mutations: a discussion. Hum Mutat 2000;15:7-12.

15. Waterworth A, Hanby A, Speirs V: A novel cell array technique for high-throughput, cell-based analysis. In Vitro Cell Dev Biol Anim 2005;41:185-187.

16. Chou TC: Theoretical basis, experimental design, and computerized simulation of synergism and antagonism in drug combination studies. Pharmacol Rev 2006;58:621-681.

17. Greene FJ, Page DL, Fleming ID, et al.: "AJCC Cancer Staging Manual (6th Edition)". New York: Springer, 2002. 
18. Campbell IG, Russell SE, Phillips WA: PIK3CA mutations in ovarian cancer. Clin Cancer Res 2005;11:7042.

19. Qiu W, Schonleben F, Li X, et al.: PIK3CA mutations in head and neck squamous cell carcinoma. Clin Cancer Res 2006;12:1441-1446.

20. Broderick DK, Di C, Parrett TJ, et al.: Mutations of PIK3CA in anaplastic oligodendrogliomas, high-grade astrocytomas, and medulloblastomas. Cancer Res 2004;64:5048-5050.

21. Hayes MP, Wang H, Espinal-Witter R, et al.: PIK3CA and PTEN mutations in uterine endometrioid carcinoma and complex atypical hyperplasia. Clin Cancer Res 2006;12:5932-5935.

22. Nakayama K, Nakayama N, Kurman RJ, et al.: Sequence mutations and amplification of PIK3CA and AKT2 genes in purified ovarian serous neoplasms. Cancer Biol Ther 2006;5:779785.

23. Oda K, Stokoe D, Taketani Y, McCormick F: High frequency of coexistent mutations of PIK3CA and PTEN genes in endometrial carcinoma. Cancer Res 2005;65:10669-10673.

24. Barbi S, Cataldo I, De Manzoni G, et al.: The analysis of PIK3CA mutations in gastric carcinoma and metanalysis of literature suggest that exon-selectivity is a signature of cancer type. J Exp Clin Cancer Res 2010;29:32.

25. Carpten JD, Faber AL, Horn C, et al.: A transforming mutation in the pleckstrin homology domain of AKT1 in cancer. Nature 2007;448:439-444.

26. Shoji K, Oda K, Nakagawa S, et al.: The oncogenic mutation in the pleckstrin homology domain of AKT1 in endometrial carcinomas. Br J Cancer 2009;101:145-148.

27. Soung YH, Lee JW, Nam SW, et al.: Mutational analysis of AKT1, AKT2 and AKT3 genes in common human carcinomas. Oncology 2006;70:285-289.

28. Chalhoub N, Baker SJ: PTEN and the PI3-kinase pathway in cancer. Annu Rev Pathol 2009;4:127-150.

29. Vanhaesebroeck B, Stephens L, Hawkins P: PI3K signalling: the path to discovery and understanding. Nat Rev Mol Cell Biol 2012;13:195-203.

30. Bae IH, Kang SW, Yoon SH, Um HD: Cellular components involved in the cell death induced by cisplatin in the absence of p53 activation. Oncol Rep 2006;15:1175-1180. 
31. Goto A, Shomori K, Ohkumo T, et al.: Hyperthermia-induced apoptosis occurs both in a p53 gene-dependent and -independent manner in three human gastric carcinoma cell lines. Oncol Rep 1999;6:335-339.

32. Shin JY, Kim JO, Lee SK, et al.: LY294002 may overcome 5-FU resistance via down-regulation of activated p-AKT in Epstein-Barr virus-positive gastric cancer cells. BMC Cancer 2010;10:425.

33. Suvasini R, Somasundaram K: Essential role of PI3-kinase pathway in p53-mediated transcription: Implications in cancer chemotherapy. Oncogene 2010;29:3605-3618.

34. Xing CG, Zhu BS, Liu HH, et al.: LY294002 induces p53-dependent apoptosis of SGC7901 gastric cancer cells. Acta Pharmacol Sin 2008;29:489-498.

35. Granville CA, Memmott RM, Gills JJ, Dennis PA: Handicapping the race to develop inhibitors of the phosphoinositide 3-kinase/Akt/mammalian target of rapamycin pathway. Clin Cancer Res 2006;12:679-689.

36. Semba S, Itoh N, Ito M, et al.: The in vitro and in vivo effects of 2-(4-morpholinyl)-8-phenylchromone (LY294002), a specific inhibitor of phosphatidylinositol 3'-kinase, in human colon cancer cells. Clin Cancer Res 2002;8:1957-1963. 


\section{FIGURE LEGENDS}

Figure 1. Expression of PI3K pathway proteins in gastric tumours. Tissue microarrays of formalin-fixed paraffin-embedded normal-appearing gastric mucosa and gastric tumour tissue were examined for expression of PI3K pathway proteins. Shown are representative low power and high power images of adjacent normal-appearing mucosa $(a, b, e, f, i, j)$ and primary tumour tissue (c,d,g,h,k,l) immuno-stained for $\mathrm{pAKT}^{\mathrm{Ser} 473}$ (a-d), PTEN (g-h), and p110 $(\mathrm{i}-1)$. Scale bars are $50 \mu \mathrm{m}$.

Figure 2. Expression of PI3K pathway proteins in gastric cancer cell lines. Tissue microarrays of formalin-fixed paraffin-embedded cell pellets of gastric cancer cell lines Kato-III (a, d, g), SNU-16 (b, e, h) and MKN-28 (c, f, i) were examined for expression of PI3K pathway proteins. Shown are representative sections immuno-stained for $\operatorname{pAKT}^{\text {Ser473 }}$ (a-c), PTEN (d-f), and p110 $\alpha$ (g-i). Scale bars are $50 \mu \mathrm{m}$.

Figure 3. Viability of gastric cancer cell lines treated with LY294002. The indicated cell lines were treated with LY294002 for 72 hours and then assessed for cell number using Alamar Blue dye. Data is expressed as \% control (no drug) and shown is the mean of triplicate determinations from a representative experiment.

Figure 4. Effect of LY294002 in combination with 5-FU or oxaliplatin on viability of gastric cancer cell lines. Gastric cancer cell lines AGS (a, b), SNU-1 (c, d) and Hs746T (e, f) were treated with a range of concentrations of LY294002 (LY) with 5-FU (a-d) or oxaliplatin (e, f) alone in combination (at a constant ratio) for 72 hours and then assessed for cell number using Alamar Blue dye. CalcuSyn software was used to derive dose-effect curves (a, c, e) and combination index (CI) plots (b, $d, f)$. Horizontal dotted line: $\mathrm{CI}=1.0$ 
Table I. Summary of clinical features and PI3K pathway alterations in gastric cancer patients.

\begin{tabular}{|c|c|c|c|c|c|c|c|c|c|c|}
\hline \multirow[b]{2}{*}{$\begin{array}{c}\text { Patient } \\
\text { ID }\end{array}$} & \multicolumn{6}{|c|}{ Clinical features } & \multicolumn{4}{|c|}{ PI3K pathway changes } \\
\hline & Age $^{a}$ & Gender $^{\mathrm{b}}$ & $\begin{array}{l}\text { Sub- } \\
\text { type }^{\text {c }}\end{array}$ & Stage $^{d}$ & Location $^{\mathrm{e}}$ & Nodes $^{f}$ & $\begin{array}{l}\text { PIK3CA } \\
\text { mutation }\end{array}$ & $\begin{array}{c}\text { PIK3CA } \\
\text { gain }\end{array}$ & $\begin{array}{c}\text { PTEN } \\
\text { loss }\end{array}$ & pAKT \\
\hline 12 & 78 & $\mathrm{~F}$ & $\mathrm{D}$ & IV & Lower & + & H1047R & No & No & High \\
\hline 46 & 45 & M & $\mathrm{D}$ & III & Lower & + & P539S & No & No & Low \\
\hline 51 & 65 & M & $\mathrm{D}$ & III & Lower & + & H1047R & No & No & High \\
\hline 5 & 85 & $\mathrm{~F}$ & $\mathrm{D}$ & III & Lower & + & No & Yes & No & High \\
\hline 10 & 75 & $\mathrm{~F}$ & I & IV & Total & + & No & Yes & No & High \\
\hline 23 & 79 & M & I & III & Lower & + & No & Yes & No & High \\
\hline 37 & 77 & $\mathrm{~F}$ & I & I & Lower & - & No & Yes & No & High \\
\hline 38 & 91 & $\mathrm{~F}$ & I & I & Lower & - & No & Yes & No & High \\
\hline 45 & 45 & M & D & II & Upper & - & No & Yes & No & High \\
\hline 47 & 71 & $\mathrm{~F}$ & D & I & Lower & - & No & Yes & Yes & Low \\
\hline 48 & 66 & M & D & II & Lower & - & No & Yes & Yes & Low \\
\hline 1 & 65 & M & D & II & Lower & - & No & No & Yes & Low \\
\hline 2 & 70 & M & $\mathrm{D}$ & IV & Lower & + & No & No & Yes & Low \\
\hline 6 & 45 & $\mathrm{~F}$ & $\mathrm{D}$ & I & Lower & - & No & No & Yes & High \\
\hline 14 & 71 & M & I & III & Upper & + & No & No & Yes & Low \\
\hline 16 & 70 & $\mathrm{~F}$ & $\mathrm{D}$ & IV & Lower & + & No & No & Yes & Low \\
\hline 17 & 65 & M & I & II & Lower & - & No & No & Yes & Low \\
\hline 18 & 71 & $\mathrm{~F}$ & $\mathrm{D}$ & III & Lower & + & No & No & Yes & Low \\
\hline 19 & 67 & $\mathrm{~F}$ & $\mathrm{D}$ & III & Middle & + & No & No & Yes & High \\
\hline 21 & 66 & M & I & IV & Lower & + & No & No & Yes & High \\
\hline 28 & 51 & M & $\mathrm{D}$ & II & Lower & - & No & No & Yes & Low \\
\hline 33 & 63 & $\mathrm{~F}$ & $\mathrm{D}$ & III & Lower & + & No & No & Yes & High \\
\hline 34 & 85 & M & $\mathrm{D}$ & III & Lower & + & No & No & Yes & High \\
\hline 35 & 71 & M & $\mathrm{D}$ & III & Lower & - & No & No & Yes & Low \\
\hline 39 & 88 & M & $\mathrm{D}$ & III & Lower & + & No & No & Yes & Low \\
\hline 40 & 64 & M & I & III & Upper & + & No & No & Yes & Low \\
\hline 43 & 74 & $\mathrm{~F}$ & I & I & Lower & - & No & No & Yes & Low \\
\hline 49 & 68 & $\mathrm{~F}$ & $\mathrm{D}$ & III & Lower & + & No & No & Yes & Low \\
\hline 52 & 47 & $\mathrm{~F}$ & $\mathrm{D}$ & III & Lower & + & No & No & Yes & Low \\
\hline 53 & 72 & M & $\mathrm{D}$ & IV & Lower & - & No & No & Yes & Low \\
\hline 57 & 74 & $\mathrm{~F}$ & $\mathrm{D}$ & III & Lower & + & No & No & Yes & Low \\
\hline 60 & 83 & M & I & III & Lower & + & No & No & Yes & Low \\
\hline 61 & 74 & M & $\mathrm{D}$ & III & Lower & + & No & No & Yes & Low \\
\hline $\begin{array}{l}{ }^{\mathrm{a}} \mathrm{A} \\
{ }^{\mathrm{b}} \mathrm{F} \\
{ }^{\mathrm{c}} \mathrm{L} \\
{ }_{\mathrm{d}} \mathrm{T} \\
{ }^{\mathrm{e}} \mathrm{L}\end{array}$ & $\begin{array}{l}\text { ren C } \\
\text { M sta } \\
\text { er, } \mathrm{N}\end{array}$ & $\begin{array}{l}\text { lagnosis } \\
\text {; M, male } \\
\text { ge (AJCC } \\
\text { liddle or L }\end{array}$ & incer & $\begin{array}{l}\text { fuse; I, } \\
\text { taging } \\
d \text { of st }\end{array}$ & $\begin{array}{l}\text { ntestinal. N } \\
\text { Ianual (6th } \\
\text { nach. Total, } \\
\text {; -, negative }\end{array}$ & $\begin{array}{l}\text { mixed } \\
\text { dition) } \\
\text { total sto } \\
\text { for lym }\end{array}$ & $\begin{array}{l}\text { ses were } \\
7])\end{array}$ & $\begin{array}{l}\text { entified ir } \\
\text { ment. }\end{array}$ & his coh & \\
\hline
\end{tabular}


Table II. Association between PI3K pathway alterations and AKT phosphorylation

\begin{tabular}{|c|c|c|c|c|}
\hline \multirow[b]{2}{*}{ PI3K alteration } & \multirow[b]{2}{*}{ Total } & \multicolumn{3}{|c|}{ pAKT } \\
\hline & & Low & High & $p^{\mathrm{a}}$ \\
\hline \multicolumn{5}{|l|}{ PIK3CA mutation } \\
\hline No & 58 & 32 & 26 & \\
\hline Yes & 3 & 1 & 2 & 0.59 \\
\hline \multicolumn{5}{|l|}{$P I K 3 C A$ gain } \\
\hline No & 53 & 31 & 22 & \\
\hline Yes & 8 & 2 & 6 & 0.13 \\
\hline \multicolumn{5}{|l|}{ PTEN loss } \\
\hline No & 37 & 14 & 23 & \\
\hline Yes & 24 & 19 & 5 & 0.002 \\
\hline \multicolumn{5}{|l|}{ Any ${ }^{b}$} \\
\hline No & 28 & 13 & 15 & \\
\hline Yes & 33 & 20 & 13 & 0.31 \\
\hline
\end{tabular}

a two-tailed Fisher's Exact test

${ }^{\mathrm{b}}$ PIK3CA mutation, PIK3CA gain, and/or PTEN loss

John Wiley \& Sons, Inc. 
Table III. Association between clinical features and PI3K pathway alterations in gastric cancer patients

\begin{tabular}{|c|c|c|c|c|c|c|c|c|c|c|c|c|c|c|c|c|}
\hline \multirow[b]{2}{*}{ Clinical features } & \multirow[b]{2}{*}{ Total } & \multicolumn{3}{|c|}{$\underline{P I K 3 C A}$ mutation } & \multicolumn{3}{|c|}{$\underline{P I K 3 C A \text { gain }}$} & \multicolumn{3}{|c|}{$\underline{\text { PTEN loss }}$} & \multicolumn{3}{|c|}{$\underline{\text { Any alteration }^{\mathbf{a}}}$} & \multicolumn{3}{|c|}{ pAKT } \\
\hline & & $\mathbf{N}$ & $\mathbf{Y}$ & $p^{\mathbf{b}}$ & $\mathbf{N}$ & $\mathbf{Y}$ & $p^{\mathbf{b}}$ & $\mathbf{N}$ & $\mathbf{Y}$ & $p^{\mathbf{b}}$ & $\mathbf{N}$ & $\mathbf{Y}$ & $p^{\mathbf{b}}$ & $\mathbf{L}$ & $\mathbf{H}$ & $p^{\mathbf{b}}$ \\
\hline \multicolumn{17}{|l|}{ Age } \\
\hline$<65$ & 17 & 16 & 1 & & 16 & 1 & & 12 & 5 & & 10 & 7 & & 8 & 9 & \\
\hline$\geq 65$ & 44 & 42 & 2 & 1.0 & 37 & 7 & 0.42 & 25 & 19 & 0.39 & 18 & 26 & 0.26 & 25 & 19 & 0.57 \\
\hline \multicolumn{17}{|l|}{ Gender } \\
\hline Male & 38 & 36 & 2 & & 33 & 5 & & 24 & 14 & & 20 & 18 & & 22 & 16 & \\
\hline Female & 23 & 22 & 1 & 1.0 & 20 & 3 & 1.0 & 13 & 10 & 0.79 & 8 & 15 & 0.20 & 11 & 12 & 0.60 \\
\hline \multicolumn{17}{|l|}{ Location } \\
\hline Non-cardia & 48 & 45 & 3 & & 41 & 7 & & 26 & 22 & & 18 & 30 & & 26 & 22 & \\
\hline Cardia & 13 & 13 & 0 & 1.0 & 11 & 2 & 1.0 & 11 & 2 & 0.06 & 10 & 4 & 0.03 & 7 & 6 & 1.0 \\
\hline \multicolumn{17}{|l|}{ Lauren classification $^{\mathrm{c}}$} \\
\hline Intestinal type & 20 & 20 & 0 & & 16 & 4 & & 14 & 6 & & 10 & 10 & & 8 & 12 & \\
\hline Diffuse type & 41 & 38 & 3 & 0.54 & 37 & 4 & 0.42 & 23 & 18 & 0.40 & 18 & 23 & 0.79 & 25 & 16 & 0.17 \\
\hline \multicolumn{17}{|l|}{ TNM stage ${ }^{\mathrm{d}}$} \\
\hline Stage I-II & 23 & 23 & 0 & & 18 & 5 & & 16 & 7 & & 13 & 10 & & 12 & 11 & \\
\hline Stage III-IV & 38 & 35 & 3 & 0.28 & 35 & 3 & 0.14 & 21 & 17 & 0.29 & 15 & 23 & 0.29 & 21 & 17 & 1.0 \\
\hline \multicolumn{17}{|c|}{ Lymph node metastasis } \\
\hline Negative & 24 & 24 & 0 & & 19 & 5 & & 14 & 10 & & 12 & 12 & & 13 & 11 & \\
\hline Positive & 37 & 34 & 3 & 0.27 & 34 & 3 & 0.24 & 23 & 14 & 0.79 & 16 & 21 & 0.79 & 20 & 17 & 1.0 \\
\hline
\end{tabular}

${ }^{\text {a }}$ PIK3CA mutation, PIK3CA gain, and/or PTEN loss

$\mathrm{b}$ two-tailed Fisher's Exact test

${ }^{\mathrm{c}}$ No mixed type tumours were identified

${ }^{\mathrm{d}}$ AJCC Cancer Staging Manual (6th Edition) [17] 
Table IV. Summary of PI3K pathway alterations in gastric cancer cell lines

\begin{tabular}{|c|c|c|c|c|c|c|}
\hline Cell Line & Morphology & $\begin{array}{l}\text { PIK3CA } \\
\text { mutation }\end{array}$ & $\begin{array}{c}P I K 3 C A \\
\text { gain }\end{array}$ & $\begin{array}{c}\text { PTEN } \\
\text { loss } \\
\end{array}$ & pAKT & $\begin{array}{r}\text { LY294002 } \\
\text { Sensitivity }^{\mathrm{a}} \\
\end{array}$ \\
\hline AGS & $\begin{array}{c}\text { Moderately } \\
\text { differentiated }\end{array}$ & E453K & no & no & High & Sensitive \\
\hline KATO-III & Signet ring cell & wt & Gain & no & High & Resistant \\
\hline SNU-1 & $\begin{array}{c}\text { Poorly } \\
\text { differentiated }\end{array}$ & wt & no & no & Low & Sensitive \\
\hline SNU-5 & $\begin{array}{c}\text { Poorly } \\
\text { differentiated }\end{array}$ & wt & no & no & Low & Resistant \\
\hline SNU-16 & $\begin{array}{c}\text { Poorly } \\
\text { differentiated }\end{array}$ & wt & no & Loss & High & Resistant \\
\hline MKN-28 & $\begin{array}{c}\text { Poorly } \\
\text { differentiated }\end{array}$ & wt & no & Loss & Low & Sensitive \\
\hline N87 & $\begin{array}{c}\text { Well } \\
\text { differentiated }\end{array}$ & wt & no & no & High & Sensitive \\
\hline GTL-16 & $\begin{array}{c}\text { Poorly } \\
\text { differentiated }\end{array}$ & wt & Gain & no & High & Sensitive \\
\hline Hs746T & $\begin{array}{c}\text { Poorly } \\
\text { differentiated }\end{array}$ & wt & Gain & no & High & Sensitive \\
\hline
\end{tabular}

${ }^{a}$ Sensitive, $\mathrm{IC}_{50}<30 \mu \mathrm{M}$; Resistant, $\mathrm{IC}_{50} \geq 30 \mu \mathrm{M}$ 
Table V. IC 50 and Effect of the combination between LY294002 and 5-FU or oxaliplatin in gastric cancer cell lines

\begin{tabular}{|c|c|c|c|c|c|c|c|c|c|}
\hline \multirow[b]{2}{*}{ Cell line } & \multirow{2}{*}{$\frac{5-F U}{I C_{50}{ }^{a}}$} & \multirow{2}{*}{$\frac{\text { Oxaliplatin }}{\text { IC }_{50}}$} & \multirow{2}{*}{$\frac{\text { LY294002 }}{\text { IC }_{50}}$} & \multicolumn{3}{|c|}{$\underline{\text { LY294002 and 5-FU }}$} & \multicolumn{3}{|c|}{ LY294002 and Oxaliplatin } \\
\hline & & & & $\mathbf{E D}_{50}{ }^{\mathrm{b}}$ & $\mathbf{E D}_{75}$ & $\mathbf{E D}_{90}$ & $\mathbf{E D}_{50}$ & $\mathbf{E D}_{75}$ & ED $_{90}$ \\
\hline AGS & 1.3 & 1.4 & 22 & 2.8 & 0.17 & 0.010 & 6.2 & 10 & 28 \\
\hline KATO-III & $>500$ & $>500$ & $>500$ & $\mathrm{NA}^{\mathrm{c}}$ & NA & NA & NA & NA & NA \\
\hline SNU-1 & 1.6 & 1.9 & 13 & 5.7 & 1.7 & 0.85 & 0.55 & 6.3 & 73 \\
\hline SNU-5 & $>500$ & $>500$ & $>500$ & NA & NA & NA & NA & NA & NA \\
\hline SNU16 & 8.7 & 21 & $>500$ & NA & NA & NA & NA & NA & NA \\
\hline MKN-28 & 1.0 & 7.9 & 22 & 4.1 & 3.0 & 2.2 & 2.5 & 2.4 & 2.3 \\
\hline N87 & 2.3 & 1.4 & 16 & 1.1 & 2.2 & 6.3 & 45 & 35 & 34 \\
\hline GTL-16 & 0.3 & 0.1 & 8.1 & 2.3 & 2.0 & 1.6 & 2.4 & 2.7 & 2.9 \\
\hline Hs746T & 22 & 86 & 20 & 1.1 & 3.0 & 8.7 & 0.62 & 0.79 & 1.0 \\
\hline
\end{tabular}

${ }^{\mathrm{a}} \mathrm{IC}_{50}=50 \%$ inhibition concentration $(\mu \mathrm{M})$

${ }^{\mathrm{b}} \mathrm{ED}_{50}, \mathrm{ED}_{75}$ and $\mathrm{ED}_{90}=$ Combination index at effective dose of $50 \%, 75 \%$ and $90 \%$ growth inhibition, respectively.

${ }^{\mathrm{c}} \mathrm{NA}=$ not available 


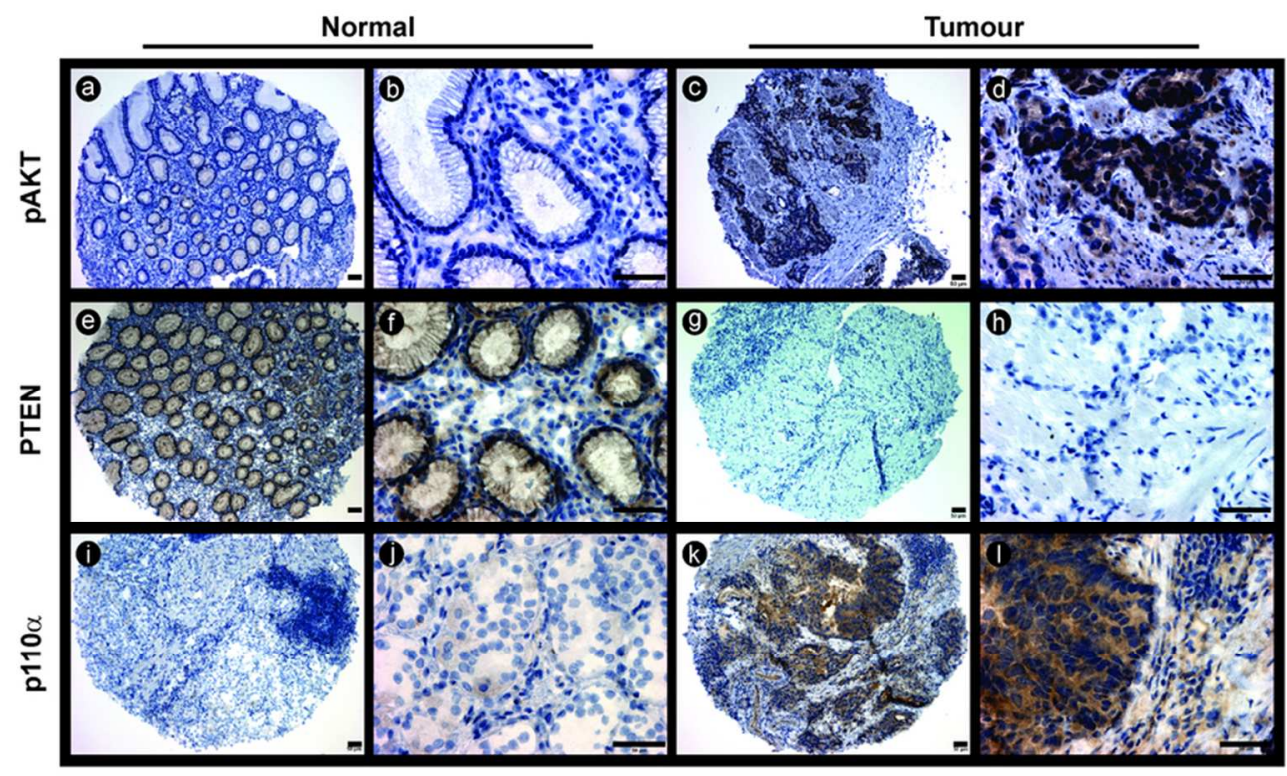

Figure 1

$78 \times 47 \mathrm{~mm}(300 \times 300 \mathrm{DPI})$

John Wiley \& Sons, Inc. 


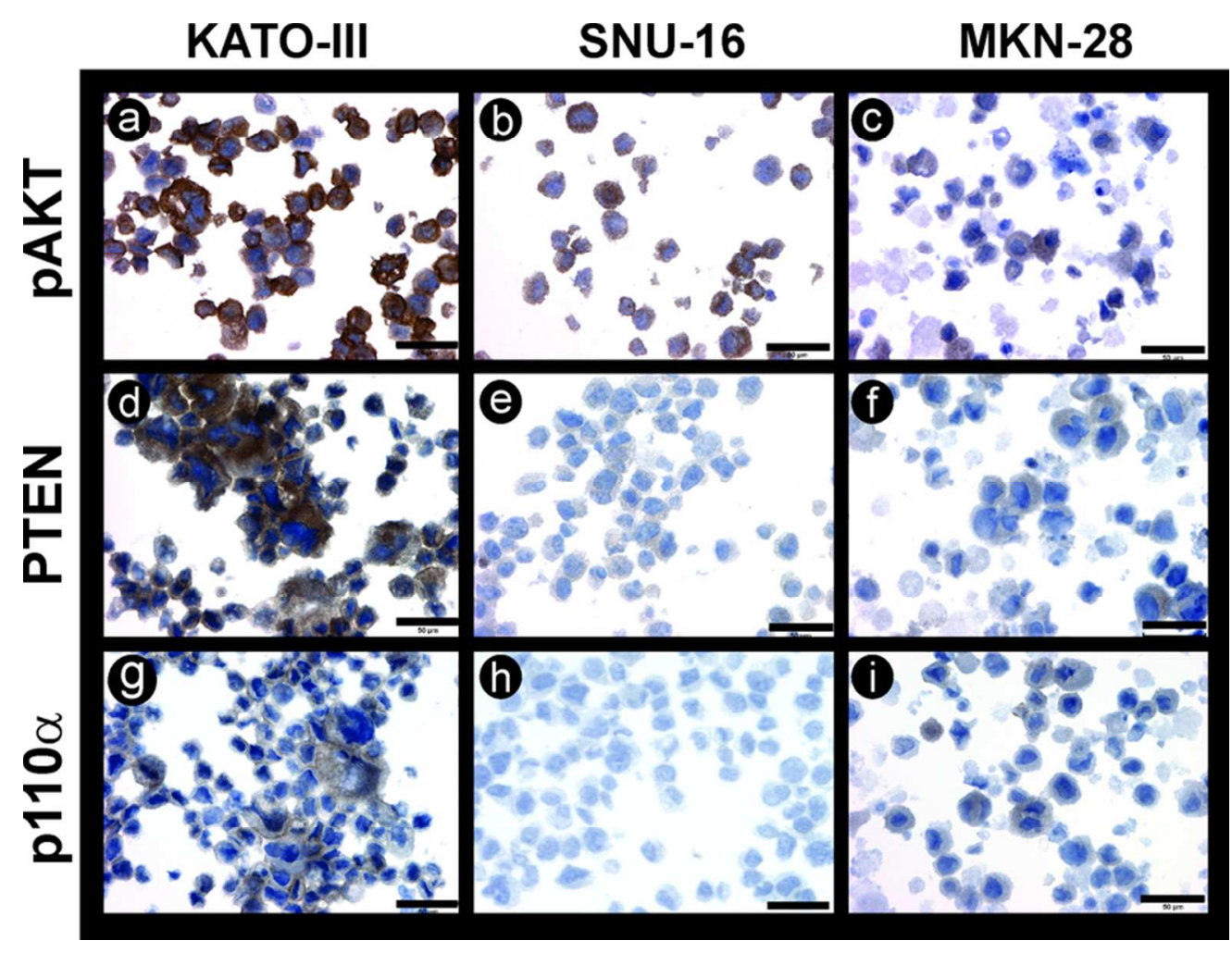

Figure 2

$76 \times 57 \mathrm{~mm}(300 \times 300$ DPI $)$

John Wiley \& Sons, Inc. 


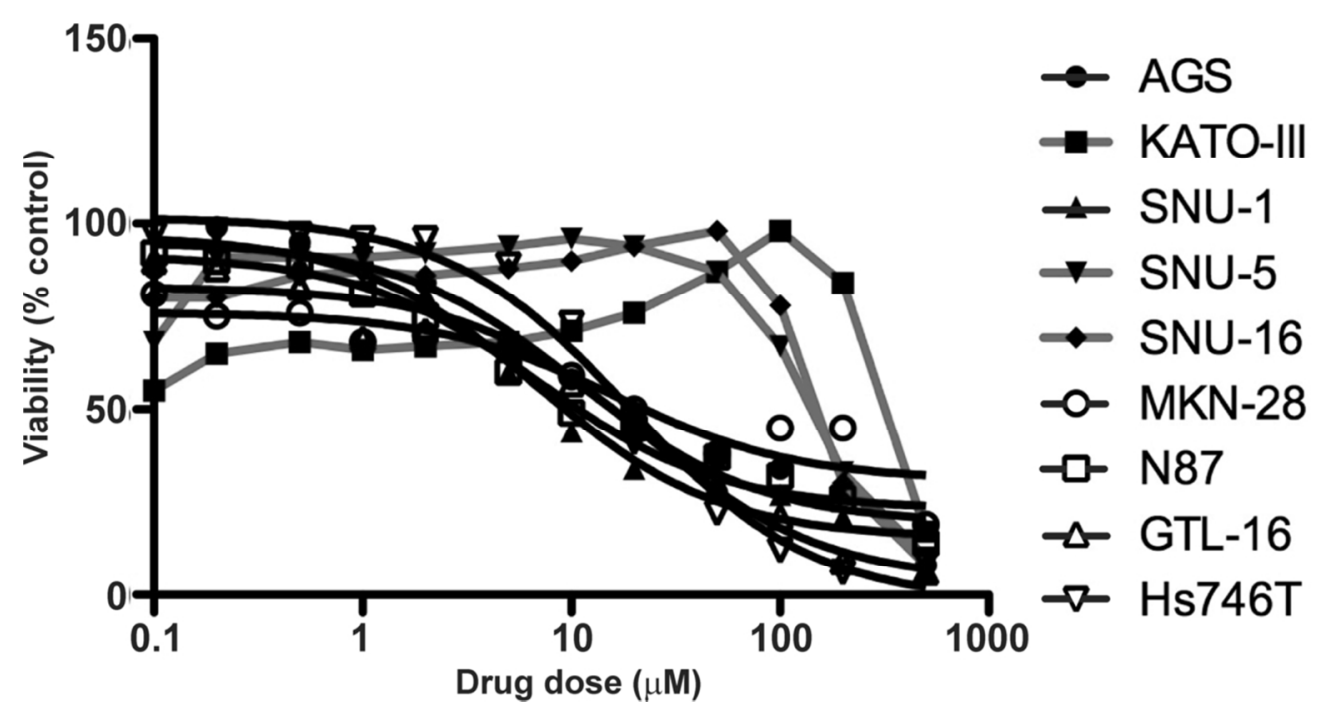

Figure 3

$52 \times 27 \mathrm{~mm}(600 \times 600 \mathrm{DPI})$

John Wiley \& Sons, Inc. 
a

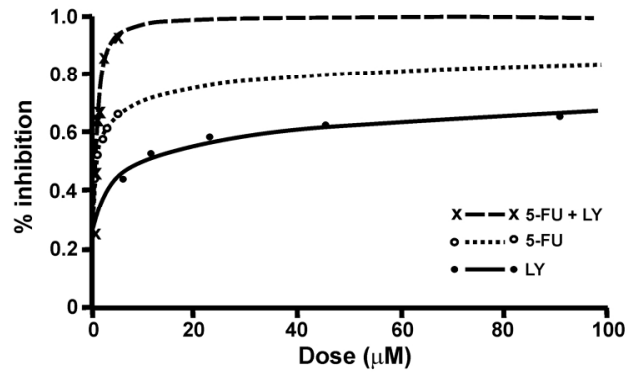

C

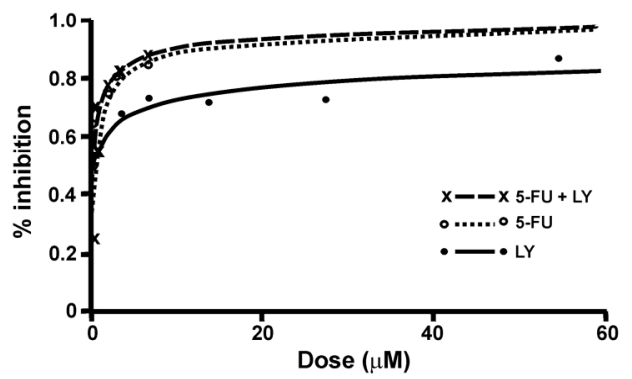

e

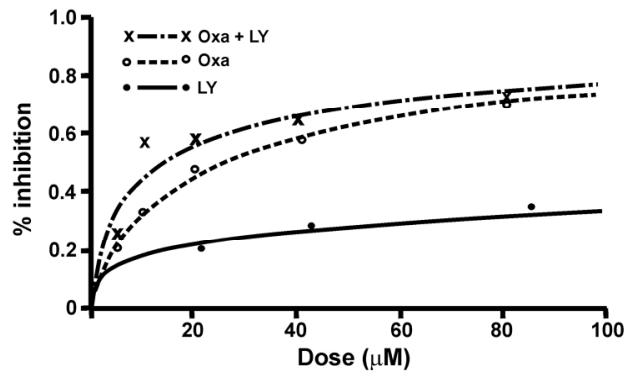

b

AGS

$\overline{0}$

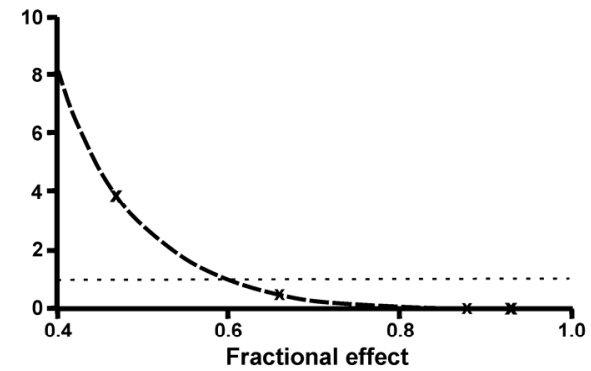

d

SNU-1

$\overline{0}$

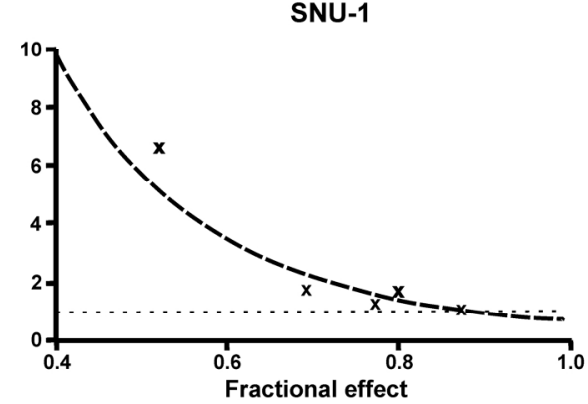

f

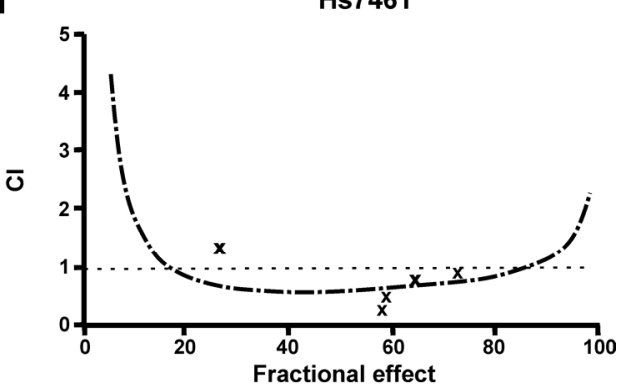

Figure 4

$101 \times 102 \mathrm{~mm}(600 \times 600$ DPI $)$

John Wiley \& Sons, Inc. 


\section{University Library}

\section{- M M N E R VA A gateway to Melbourne's research publications}

Minerva Access is the Institutional Repository of The University of Melbourne

Author/s:

Tran, TN;Brettingham-Moore, K;Duong, CP;Mitchell, C;Clemons, NJ;Phillips, WA

Title:

Molecular changes in the phosphatidylinositide 3-kinase (PI3K) pathway are common in gastric cancer

Date:

2013-08-01

Citation:

Tran, T. N., Brettingham-Moore, K., Duong, C. P., Mitchell, C., Clemons, N. J. \& Phillips, W. A. (2013). Molecular changes in the phosphatidylinositide 3-kinase (PI3K) pathway are common in gastric cancer. JOURNAL OF SURGICAL ONCOLOGY, 108 (2), pp.113-120. https://doi.org/10.1002/jso.23357.

Persistent Link:

http://hdl.handle.net/11343/123671 